\title{
Sexual Education in Schools in Portugal: Evaluation of a 3 Years Period
}

\author{
Margarida Gaspar de Matos',2,3, Marta Reis1,2,3, Lúcia Ramiro1,2,3, José Luís Pais Ribeiro',4, \\ Isabel Leal1,5 \\ ${ }^{1}$ Sociedade Portuguesa de Psicologia da Saúde, Lisboa, Portugal \\ ${ }^{2}$ Equipa Aventura Social/Universidade de Lisboa, Lisboa, Portugal \\ ${ }^{3}$ Centro da Malária e Doenças Tropicais/IHMT/UNL, Lisboa, Portugal \\ ${ }^{4}$ Faculdade de Psicologia e Ciências da Educação/Universidade do Porto, Porto, Portugal \\ ${ }^{5}$ ISPA-Instituto Superior de Psicologia Aplicada, Lisboa, Portugal \\ Email: margaridagaspar@netcabo.pt
}

Received 27 May 2014; revised 1 July 2014; accepted 13 July 2014

Copyright (C) 2014 by authors and Scientific Research Publishing Inc.

This work is licensed under the Creative Commons Attribution International License (CC BY).

http://creativecommons.org/licenses/by/4.0/

c) (i) Open Access

\section{Abstract}

Sexual education is crucial for reducing sexual risk behaviors (or at least not to enable their increase). The goal of this study was to evaluate the implementation of sexual education in schools. For the quantitative study, all schools (clustered in Schools Organic Units-SOUs) in mainland Portugal were invited to participate. Study 1-A total of 428 school principals, 424 coordinating teachers of health education, belonging to 428 Organic Units (OU), which correspond to $53 \%$ of the Portuguese public SOU, corresponding to 617,701 students and 60,595 teachers participated in the quantitative study. Study 2 -For the qualitative study, interviews were conducted. Analysis of the results of both studies emphasized that Law $n .^{\circ} 60 / 2009$ ( $6^{\text {th }}$ August) is being fulfilled with regard to the implementation of sexual education as well as the number of hours established for its implementation. In general the SOUs organized an office that provides information and support for students and manages its functioning. The implementation of the Law is, overall, ranked as good/very good (83.7\%). However, during the qualitative study, school principals and teachers emphasize that SOUs are making a huge effort to implement the Law, some of them questioning their ability to continue this process due to the present conditions. Principals and teachers reported the need to "revitalize" this area, underlining the need to maintain the Law and one annual "Call" from which the Ministry of Education and Science receives proposals for funding schools for projects in the area of health promotion, and teacher training.

\section{Keywords}

Adolescents, Sex Education, School, Sexual Risk Behaviors, Health Promotion 


\section{Introduction}

In Portugal policy guidelines define sexual education as an "intentional formal and structured approach regarding a set of topics related with human sexuality” (M.E. \& M.S., 2000; GTES, 2005; 2007; Matos \& Simões, 2010). According to these researchers sexual education is essential to a healthy and fully human development and is related to healthier outcomes not only in the area of sexual and reproductive health, but also in the area of interpersonal gendered relationships.

Regardless the importance of family in such topics, other settings and agents are involved in human development and sexuality and therefore have specific roles (Currie et al., 2012; Matos et al., 2011) on sexual education. Thus sexual education cannot be limited to family, but instead it must include young people, schools, youth organizations, local authorities and other agents that are involved in the socialization of young people (Reis, 2012). Since children and adolescents spend a great period of their time in school and it is a privileged setting where there are plenty of technicians specialized in education, besides all the necessary resources to develop sex education (GTES, 2007; Ramiro, 2013), several studies point out that school programs that include an ecologic and participative approach are the most efficient ones (Matos, Sampaio, Baptista, \& Equipa Aventura Social, 2013).

In 2009, Portugal developed a new legislation regarding sexual education (Law n. ${ }^{\circ} 60 / 2009$ from $6^{\text {th }}$ of $\mathrm{Au}-$ gust). This law was regulated by the ministerial order $n .^{\circ} 196-A / 2010$ (from $9^{\text {th }}$ of April). According to this legislation 1) every Portuguese pupil from the $5^{\text {th }}$ to the $12^{\text {th }}$ grade, should have a period of schooling time devoted to sexual education. Furthermore, 2) this time should be quite participated by pupils themselves, should be focused on knowledge and on competences, should be developmentally adequate and have a progression along schooling, that should be evaluated. 3) Teachers responsible for this area should have a specific training. Furthermore, 4) all schools should nominate a teacher to coordinate this dynamic and, 5) when possible (and mandatory in secondary schools) schools should implement a health office, where pupils could be heard in an individual basis, if necessary. This legislation was approved on the basis of promoting sexual health well-being and preventing unplanned teen-agers pregnancy, abortion and sexual transmitted infections. Once approved back in 2009 it becomes compulsory in every school. Schools should prepare their yearly plan including sexual health and send it in a yearly basis to the Ministry of Education.

The goal of the present study was to evaluate the implementation of sexual education in Portuguese schools, in order to inform and support sexual education policies. This evaluation was requested in the national legislation (the process should be evaluated after an experimental period), and was object of an external evaluation carried out by an external group of researchers, with the objective of assessing which of the issues requested in the legislation were or not fulfilled, how and why. The public call regarding this evaluation had a specific set of items that should be a focus of an evaluation. Because it was an external evaluation, the government had no power or interference on either the methods or the analysis and discussion of the results of the evaluation, nor had access to the data files or schools answers.

\section{Methodology and Research}

\subsection{Participants}

Study 1 -National wide quantitative study

Concerning the first part of the study — the quantitative study — all of the 811 Portuguese public Schools' Organic Units (SOU) were invited to participate, on a voluntary and anonymous basis. In Portugal public schools are organized in "Organic Units" that share a lot of administrative and teaching resources. SOUs have a vertical organization including children from pre-school to $12^{\text {th }}$ grade. Some SOUs are quite little including only one school of each type (Pre-school, 1, 2 and 3rd cycles and secondary), others are bigger including 2 or more schools in each type.

Although answering to the questionnaire was not compulsory due to the anonymity of the procedure, all national schools from grade 5 (10 years old) to grade 12 (17 years old) were invited to participate. There was an attempt to include private schools that failed due to the specific logistic and different legislation that rule those schools and that prevented the communication with them. In the end, a total of 428 principals and 424 teachers (teachers specifically in charge of the coordination of health education in their SOU) all belonging to public schools, participated in this study.

Considering the national population clustered in 811 SOUs, error was estimated at 3.33\% and 3.36\%, respectively, and confidence level at $96.7 \%$ and $96.4 \%$, respectively (Navidi, 2010). The participant SOUS integrated a 
total of 617,701 pupils and 60,595 teachers.

Study 2-Interviews and focus groups in schools

In a second part of the study - the qualitative study -5 SOUs were randomly selected in each of the national regions, and then one in each region was chosen. Therefore, one school in each region was visited and interviews or focus groups were held with school principals and teachers/pupils and parents, respectively.

\subsection{Instruments}

Instruments included questionnaires and guidelines for the interviews and focus groups.

Study 1

Questionnaires were derived from the items of the national evaluation call. For each of the items included in the evaluation "call”, was derived a question/ statement that would allow the team of researchers to understand each situation. This questionnaire included objective questions like “Do your school/SOU has a health Office?”, and by using Likert like scales "In your opinion how would you rate the implementation of sexual education in your school/ SOU?” (1-very bad to 5-very good).

Study 2

Guidelines for the interviews and focus groups were based on a SWOT analysis (Pickton \& Wright, 1998; van Wijngaarden, Scholten, \& van Wijk, 2010), mainly the participants were requested to speak about what were the main strengths in the process of implementation of sexual education in schools, and what were the main difficulties. Individual interviews were conducted with school principals and focus groups with teachers/pupils/parents (Matos \& Gaspar, 2002; Matos, Gaspar, Vitória, \& Clemente, 2003). Results from this study were only reported in a basis of searching for new incidents or facts not yet reported by means of the questionnaires or that could severely raise doubts on these results.

\section{Results}

\subsection{Study 1-Quantitative Study}

All 811 Public SOUs were invited to participate. From those, 428 Organic Units (OU) participated in the study. All grades were represented in this evaluation that targeted 617,701 pupils, the majority of Portuguese nationality $(96.8 \%)$.

According to school principals, to what extend and how was sexual education implemented in Portuguese public schools?

According to school principals (428 principals answered the questionnaire), the implementation of sexual education in the SOU has been good or very good (57.5\% and $26.2 \%$ respectively). From all areas of health education, sexual education is the more frequently addressed (98.6\%) followed by nutrition (97.7\%) and substance use (92.8\%).

According to school principals, the majority of the class councils (which are constituted by all the teachers of a certain class) have a sexual education project (65.7\%) and a teacher who is specifically responsible for sexual education in that class (72\%). This project is reviewed by the coordinator of health education in the SOU (87.4\%), who is also responsible for its supervision (85.7\%). In the majority of the SOU (82.2\%), all the pupils had sexual education in the last 3 years. The evaluation of the pupils is achieved considering the percentage of pupils involved in the sexual education activities (59.8\%).

The majority of the SOU (83.2\%) complied with at least the minimum number of hours of sexual education according to the national Law. In order to select teachers responsible for sexual education school principals mentioned specific training (41.4\%), motivation (27.6\%) and prior experience $(27.1 \%)$.

Regarding the implementation of strategies, lectures were the most popular (93\%), followed by transdisciplinarity (77.1\%) and participative methodologies (72.4\%).

As expected, once human reproduction is since decades part of the national curricula, "Natural Sciences” was the most frequent curricular allocation to sexual education in third grade (61.9\%) and Biology in secondary level, (31.8\%).

Referring to involvement in sexual education, principals assessed teachers' (51.6\%), pupils’ (57\%), principals' (51.6\%) and the health center (46.3\%) has having a very good involvement, while parents' (49.3\%) and their associations' (43\%) has been fair/weak; and students’ associations bad (25.2\%) or fair (40.2\%). 
School principals identified, as the main strategies to promote the involvement of the community, the cooperation of school principals (51.6\%), pupils' participation in sexual education topics (48.1\%), teachers' training (48.6\%) and external partnerships (55.3\%).

According to school principals, to what extend and how were the School Health Offices implemented in Portuguese public schools?

Other school resources include the School Health Office $(79.0 \%$ and $48.6 \%$ in third grade and secondary level, respectively) and lectures by agents external to schools ( $86.7 \%$ and $54 \%$ in third grade and secondary level respectively).

Regarding the School Health Office, principals considered that their implementation has been good/very good (59.8\%).

Those health offices include a multidisciplinary team of 2 - 5 members (preferentially 3 members (23\%), predominantly teachers (89\%); psychologists (61.4\%) and nurses (58.2\%)). Most of them (71.5\%) function until 6 hours a week.

Health Offices have several resources, bibliography (77.3\%) internet access (76.9\%) and didactic sexual education games (60\%). Mostly, they are directed to individual support (85.5\%). In addition, most Health Offices have partnerships with local health centers (85\%).

According to school principals, how was the evolution of the process of implementation of sexual education in Portuguese public schools in the last 3 years (after the approval of the law)?

Referring to the last 3 years, $56.8 \%$ of the principals considered that sexual education has been progressively integrated in the SOU culture.

They considered that the implementation of sexual education was very good in $42.5 \%$ of SOU in 2010/2011; $56.3 \%$ of SOU in 2011/2012 and 54.9\% of SOU in 2012/2013.

According to school health coordinator teachers, to what extend and how was sexual education implemented in Portuguese public schools? Basically do they confirm or not the principals descriptions and opinions?

The answers of the coordinating teacher of health education (424 coordinating teachers answered the questionnaire), basically confirm the descriptions and opinions of their principals, although questionnaires were both anonymous and independent as said in the methods section. Here will be shortly described a few features that were specifically addressed to teachers. Most stated that they were involved in sexual education (93.4\%), they have specific training (87.3\%), that they assessed as good/very good (88.2\%). They referred that they feel overall comfortable addressing sexual education topics (73.8\%), and they considered having the scientific (69.3\%) and the pedagogical skills (68.4\%) to be involved in.

According to the majority of the coordinating teachers of health education (72.6\%), all pupils in the adequate age considered by law had sexual education in the last 3 years, and most of them were evaluated through the registered participation in those activities (72.9\%). The coordinating teachers of health education considered the relation that they established with pupils as good (59.4\%) and with their families as fair (50.2\%).

The collaboration with the health center was rated as very good (50.9\%). The majority of joint actions included the visit of a professional to lecture pupils (82.8\%), and printed information such as pamphlets (74.3\%), the reference of pupils with specific individual needs (73.1\%), and the request of specific training for teachers (55.2\%).

According to the coordinating teachers, how was the evolution of the process of implementation of sexual education in Portuguese public schools in the last 3 years (after the approval of the law)?

Referring to the last 3 years, $59.9 \%$ of the coordinating teachers considered that sexual education has been progressively integrated in the SOU's culture.

They considered that the implementation of sexual education was preferentially very good in $57.3 \%$ in 2010/2011; 73.8\% in 2011/2012 and 75.8\% in 2012/2013.

\subsection{Study 2-Qualitative Study: Individual Interviews and Focus Groups}

In the second part of the study—-the qualitative study— 5 SOUs were randomly selected in each of the national regions, and then one SOU in each region was chosen, visited and interviews or focus groups were held.

Meetings with the school principal, the coordinating teacher of health education, a representative of the Parents' Association and a representative of the Students' Association as well as stakeholders were requested. Each of these types of participants were heard separately (first the principal, then group of teachers, then groups of pupils, groups of parents and if possible group of partners in the community). 
Five visits were carried to five SOUs, one in each Portuguese geographic region and the guidelines for interview and focus group (mostly strengths, difficulties and suggestions) were applied. In each of the schools 4 or 5 meetings were held with the different groups of participants. In what principals and coordinating teachers are concerned the interview aimed at gathering new information that could have missed in the questionnaire and give it a proper context. Regarding the other participants, besides this contextualization, researchers were in seeking for any new and not yet reported fact of opinion, once, due to the evaluation process restrictions in terms of schedule and deadlines, information issue from pupils, parents and partners in the community was not possible to gather during Study 1.

What did school principals add, when requested to talk about the strengths and the difficulties of the implementation process?

1) School principals revealed themselves clearly overburdened with administrative tasks that do not allow them more active involvement. They respond to specific, simple requests that do not involve money. They mentioned that the more the dynamics of sexual education are part of the routine of the SOU, the easier, the best quality and the best sustainability it has. They also emphasize the need to insist on teachers' training, and stress the importance of supervision. On the one hand, "the school needs to fix its critical mass, every year we receive new teachers and we must always initiate the process". On the other hand, older teachers tend to resist more to work sexual education topics. Regardless, the ones that are engaged in the process have more training and experience.

Another important difficulty they report is related to boosting sexual education after the ministry ended the NDCA (non-disciplinary curricular areas), where it was easy to develop sexual education. According to the school principals, the activities should be compulsory; stressing that without the NDCA it is very difficult to ensure the stimulation of sexual education.

What did coordinating teachers add, when requested to talk about the strengths and the difficulties of the implementation process?

2) The coordinating teachers with long experience in health education demonstrated some dismay at sexual education and tiredness due to hard work. According to them, parents and students show little involvement, and little recognition in general: "It lacks recognition, accountability, and school culture (...) in the third grade, without NDCA it is difficult to find space and time for health education (...) teachers prefer not to jeopardize the accomplishment of their programs; further more they prefer to delegate sexual education to external agents, avoiding taking the responsibility for themselves and not affiliating to difficult tasks”.

They also mentioned the need for training and the need for supervision afterwards to ensure that training remains updated and is followed by action, since according to them it is often mentioned that some teachers have training but do not feel confident or able enough to address topics of sexual education with their students. It was mentioned, either by teachers or pupils the need for health promoters to have, in addition to specific training, specific profile (e.g. ability to develop good interpersonal relationships, to be at ease in addressing sexual education topics, ability to prevent and manage conflicts with assertiveness, ability to recognize the topics that are important for pupils). The attitude of teachers who attend health promoting actions held by colleagues with streamlined training ranges from: not authorizing activities of sexual education in the subjects they teach (the only existing alternative when there is no NDCA) with the excuse they have contents to teach and they are already out of schedule or authorizing it but most of the time not getting directly involved. When they authorize it, they may show two different attitudes - either they exhibit a negative attitude (either passive or even somewhat competitive) or a positive attitude, getting actively involved. In the latter case the effects are exponentially beneficial for pupils.

It was also referred that the quality of the partnership with the local health centre depends greatly on the importance the managers of each health center give to sexual health, therefore ranging from no relationship whatsoever to a very close and effective network with well-defined contact interaction. The planning of the actions of health education is done at the beginning of the school year so that there is plenty of time to inform everyone and that of is scheduled avoiding periods of students' formal evaluation.

The annual provision by the Ministry of Education and Science for funding for the implementation of health education (in which sexual education is part) was considered essential for the sustainability of sexual education.

Teachers (as well as school principals) state that, overall, NDCA had a positive effect on the functioning of the Law n. ${ }^{\circ} 60 / 2009$ since they enabled sexual education to be developed without interfering with the curricula of other subjects, even though, quite often, the selection of topics was not done in a structured way due to the 
fact that they also enabled the opportunity to work specific problems of the class (for example, issues of discipline, conflict resolution). In addition, the topics that are addressed in these areas depend on the needs that emerge on a daily basis. The selection of the contents of these NDCA often follows the urgency of everyday problems instead of a fixed plan to develop the skills established in the curriculum, thus not favoring a systematic and sustained plan to ensure the compliance of Law n. ${ }^{\circ} 60 / 2009$. Because the NDCA were withdrawn from national curricula, schools often have to create an area which is a school option in order to guarantee sexual education. In some cases, though, these school options is permanently dedicated to SU the resolution of other objectives in the teaching/learning process.

The SOUs generally have a Health Office for Information and Students' Support, with facilities, equipment, materials and a fixed schedule. The overall impression is that these offices serve as the center of planning the actions of health promotion in the SOU and are used by more technical staff than the pupils themselves.

Several reasons explain why pupils' don't frequently attend the health office: a) students may not know it exists or where it is located; b) they may not know what its goals are and that one of them is specifically giving support to them and helping them with their problems, within a private and anonymous setting; c) the office may be lacking dynamism; d) the teachers that are part of the office's team may lack training or may be involved in too many other school activities lacking the time to stimulate the office; the technical staff (like psychologists and nurses) that are part of the office's team may lack the necessary training (not conveying confidence to pupils) or they may be involved in too many professional activities lacking the time to stimulate the office; and e) there is a wide range of more appealing and more efficient structures outside the school.

Overall, one gets the impression that pupils ought to play a more active role in the Health Office for Information and Students' Support, whether defining the actions to be implemented or tutoring younger pupils. They state they are motivated to take an active role in the health office and that they consider it crucial in the educational process but their stay in school is not long enough for them to design and implement a plan, so their involvement lacks sustainability.

As for parents' involvement in the health office, results suggest that it is none. This result is corroborated by the focus groups with representatives of Parents' Associations.

What did the pupils comment, when requested to talk about the strengths and the difficulties of the implementation process?

3) Though the participation of representatives of Students' Associations in the quantitative study was very small, their participation was massive in the focus groups. Some explained that elections for the associations occur in October of each year and, therefore, between September and November (the period when the quantitative study occurred) it is quite difficult to have any response from Students' Associations, and even if there is a response it is in general from newly — elected representatives and therefore it might not be the most accurate one. They argue that the board of the SOU has to take the lead continuously and act as a permanent structure while Students' Associations are involved in the dynamics of sexual education on an annual basis. Representatives of Students' Associations reported that sometimes sexual education classes are seen as leisure activities by pupils. They also mentioned that it often happens that boys and girls find difficult to understand and get interested in gender-specific topics (e.g. issues related to menstruation and fertile period) and it is necessary to address sexual education together, apart that both boys and girls admit profiting from knowing about all topics, no matter they are gender-related. They also referred that in some SOU, the environment is not sexual education friendly, which takes pupils who like to participate in sexual educations actions to feel inhibited, sometimes even mocked by colleagues. They identify thematic activities such as "The week of sport, food..." as the most easily remembered. Some of them expressed some disbelief by the fact that teachers of other subjects besides Natural Sciences or Biology could get involved in health/sexuality sessions, showing the misconception that these teachers though willing must not be effectively prepared. Thus, representatives of Students' Associations were not aware of additional training that a teacher of any discipline may have, or the fact that health and sexuality are related to "all subjects".

Some representatives of the Association of Students of secondary level considered the existence of NDCA in secondary level to be redundant, since they had already done this kind of work in previous years, mainly in Project Area and Accompanied Study. Nevertheless, they admitted that pupils that attend courses not related to Biology—such as arts, humanistic and professional courses—might not have opportunity to have health and sexual education.

In order to get pupils motivated and engaged in sexual education, they proposed that the technologies of 
communication and information, particularly Facebook, webpages, online platforms, electronic panel in the SOU, and a collective email are used. They add to these good signaling and tours to the Health Office, as well as peer training, animations of the school's atrium, and taking advantage of the day of enrollment to disclose the SOU's resources and how to use them.

When asked about specific strategies they considered to be effective, they mentioned true stories, i.e. talking to people with experience in the field-from caregivers for people affected by a specific problem to the people with that specific problem (as long as they agreed to testify about their life)—or that they were shown videos made anonymously with these people, so that they have-according to them-credible information. They would like the SOU to have an interactive website ("second life" type) where they could identify all SOU sites from home.

Most representatives of Students' Associations that participated in this study did not know where the Health Office for Information and Students' Support was located, or if they knew they were not aware of its goals, nor did he feel comfortable contact the technicians involved, suggesting that someone's attendance should be scheduled by email or via an online platform.

What did pupils' parents comment, when requested to talk about the strengths and the difficulties of the implementation process?

4) The participation of representatives of Parents' Associations was very limited in the qualitative study too, although in several cases the teachers that participated in the interviews were parents of pupils either in their SOU or in other SOU of the same geographical area. The overall experience was that parents were little involved in the SOU's activities and generally schools don't favor a continuous work with parents, and the work that is privileged was much less focused on extra academic subjects and activities. The school board reported scarce meetings with the Parents' Association, so there is an urgent need to revitalize this network. As for teachers, beyond their function of class directors, little contact and actions were developed in collaboration with parents. As for the Parents' Associations, these seem to be sharply focused, almost exclusively, in problems related to indiscipline and conflict resolution. However, the (few) parents that presented themselves as considerate about a comprehensive education, revealed the intention to intervene more actively in the SOU, but referred not knowing how to do it. They also were of the opinion that a wider mobilization of parents in the SOU would be useful, i.e. that besides the purpose of complaint, a real partnership should be favored. Nevertheless, they identified major difficulties, such as how to establish a truly representative leadership among other parents, particularly in SOU which result from various schools that have been grouped and therefore have several levels of education with their inherent features.

What did partners in the community comment, when requested to talk about the strengths and the difficulties of the implementation process?

5) Many SOU usually make use of outside organizations to revitalize health/sexual education. Initially, the external agents were almost exclusively involved in the NDCA, where they implemented their sessions. With the end of the NCDA, the SOU chose to use these external agents within the context of the other subjects, in particular Natural Sciences/Biology. These agents may be funded by SOU, by local authorities, may belong to organizations under the supervision of the Ministry of Health (as is the case of health centers), and sometimes have their own financing and they propose the activities themselves to the SOU (as is the case of APF and other NGOs with funding from the Ministry of Health). According to the interviews and focus groups, these agents usually have a specific action such as, for example, addressing sexual education topics with all classes of the 10th grade or developing a set of 2 - 3 sessions per class, over school year.

They seek to work with teachers and considered these generally very welcoming. In their opinion teachers are not more involved in sexual education because, in general, they are overburdened by bureaucracy. They try to articulate with the SOU's psychologist (if any), who most frequently is also dealing with workload and has, in general, other specific functions related to vocational guidance. Some SOU count on another resource as interns from medical universities, dovetailing with the coordinating teachers of health education at the SOU to support this health/sexual education mission. All reported to evaluate their action. In general, these actions are also evaluated by the teachers and they exchange and discuss the results of evaluation regularly. These agents usually participate in specific thematic days (or weeks) specific, e.g. nutrition, health, exercise, smoking prevention, HIV/AIDS, alcohol and substance abuse, which generally include actions such as fairs, exhibitions and conferences. In their opinion, though these actions can involve some students, because they are extra activities they do not involve as many pupils as targeted, and consider that these do not necessarily involve the ones who are the 
most vulnerable. They referred being concerned that there are no guarantees that all students have access to sexual education at present; and they mentioned not being generally involved in the evaluation of their intervention in the SOU.

\section{Conclusion}

The results of both the descriptive statistics of the responses to the questionnaires (the first phase of the study) and the individual and group interviews (the second phase of the study), emphasize that Law n. ${ }^{\circ} 60 / 2009$ is being complied regarding the content of sexual education and recommended course load in the SOU. Overall, the SOU implemented an Information Health Office for Information and Students' Support and they manage its organization. The implementation of the Law is generally classified as good/very good.

Accounts from representatives of Parents' Associations and Students' Associations as well as from other various stakeholders who agreed to participate in this study corroborated these results, school principals and teachers emphasize that SOU are making a huge effort to fulfill the Law, some questioning the ability to continue this process in the present conditions.

Teachers considered themselves too overloaded by overwork and too undervalued and little recognized by the community. They regretted the extinction of the NDCA (non-disciplinary curricular areas), since without these they are forced to use teaching hours from their subjects to implement the sexual education Law. They emphasized that presently sexual education is mostly maximized through two subjects (Natural Science and Biology, in third grade and secondary level, respectively) but this leads to the fact that secondary students that are enrolled in arts, socio-economic sciences, humanities and languages, as well as those attending professional courses, do not have an easy access to sexual education. Teachers also regretted the withdrawal of the reduction of hours allocated to their lective workload when they were given the function of coordinating teacher of health of their SOU, which implies an overload of work and consequently implies also the hiring of teams outside the SOU in order to guarantee the implementation of the Law n. ${ }^{\circ} 60 / 2009$. This strategy does not promote the evolution of the SOU in terms of autonomy and the development of its own "health" culture.

Students (representatives of Students' Associations) reported some fatigue since, according to them, the exact same sexual health topics are addressed every year and without any progression. The secondary school pupils would like to be more involved in peer training activities. Students, teachers and parents suggested that their progression from third grade to secondary level is little and that sexual education is too repetitive, even suggesting that it is necessary to ensure that it does not focus solely on biological aspects of reproduction and sexually transmitted infections. School principals and teachers reported a need to "refresh" sexual education, giving new impetus to the Law and its implementation, stressing the need to maintain the annual official notice from which the Ministry of Education and Science receives proposals from the SOU for funding projects in the area of health promotion (and sex education) and training of teachers in these areas.

\subsection{Recommendations}

\subsubsection{For the Ministry of Education and Science}

1) On the basis of the results of the implementation of Law n. $60 / 2009$ and the Ministerial Order $n .{ }^{\circ}$ 196-A/2010, is recommended that SE in school context keeps being favored as a priority, and that the necessary conditions, such as the training of teachers and parents are ensured.

2) It is recommended that the Law n. ${ }^{\circ}$ 60/2009 and the Ministerial Order n. ${ }^{\circ} 196-A / 2010$ are maintained, although a debate is recommended, possibly when presenting the results of this evaluation, addressing the major strengths and weaknesses and designing proposals in order to overcome weaker points. To do so a broad debate about the importance of this matter and the importance of involving all stakeholders in the school environment (such as school principals, teachers, parents and students) are crucial.

3) The training of technicians is also recommended. While focusing primarily on teachers, it should also include all the specialists involved in the SOU, like psychologists, physicians, nurses, social workers and operational workers, etc.. For this purpose, it is recommended that the Ministry of Education and Science assumes a leadership, coordination the synergies with training centers and higher education institutions.

4) It is recommended the implementation and enhancement of research studies that evaluate SE in school context, especially in middle school, because research areas still show gaps that need to be understood, such as better understanding the motivation and competence of adolescents to take preventive behaviors; understanding 
the relational and emotional sphere of sexuality; the role of family, friends, school and community in this process; and how to achieve permanent changes associated with health and well-being.

5) The Health Offices for Information and Students' Support should be extended to Universities. These offices should consist of multidisciplinary teams that include relevant partnerships with related structures (e.g. health centers, hospitals, associations related to sexuality and to this age period), making use of the latest technologies (especially the internet) and peer training, supporting the implementation of universal prevention campaigns, raising awareness and training skills related to sexuality. These offices could also have a strong role in teacher's initial education as well as resource centers to support teachers after their initial training.

6) Maintaining the cooperation protocol between the Ministry of Education and Science and the Ministry of Health, and giving a systemic framework for collaboration between the SOU and Hospitals, Health Centers, Public Health Units and Family Health Units are recommended.

\subsubsection{To the General Directorate of Education}

1) It is recommended to maintain sexual education compulsory by creating conditions for it to be sustainable: a) the annual official notice, b) reduction of hours allocated to coordinating teachers lective workload, maintenance of the coordinating teacher's role, c) reduction of hours allocated to teachers non-lective workload, d) the resettlement of the non-curricular areas, e) the inclusion of a component of evaluation of the process, of the students, and of the SOU, f) teacher training, and g) access to a global organization to share materials at regional or even national level.

2) It is recommended that legislation such as Law n. ${ }^{\circ}$ 139/2012 and the Normative Order n. ${ }^{\circ}$ 7/2013 are widely disseminated and discussed at the level of the SOU, sensitizing directions and optimizing the potential of some of the points previously identified, namely 1) additional supply (choice of organic unity) scheduled for 1.st, 2.nd and 3.rd grades, 2) the flexibility and autonomy allowed in managing lective and non-lective teachers workload, 3) mechanisms for obtaining additional credit hours, particularly in the development of projects in the school organic unity.

\subsubsection{For principals of the School's Organic Units (OU)}

1) Management of the resources of the organizational unit is recommended, systematically including as active partners teachers, the students themselves, their parents, operational workers, other health and education professionals, the health center, the youth center, the commission on protection of children and youth at risk, the parish councils.

2) Reinforcing the existence of an Information Health Office for Information and Students' Support is recommended reconsidering its role in terms of resources management, active student participation, collaboration with families and other agents of the community (health center, youth center, commissions on protection of children and youth at risk, parish councils).

3) It is recommended a strong investment in training technicians in the area of sexual education, one that includes an initial training, both at the Centers for Teacher Education, and in the Institutions of Higher Education (Initial Teacher Education and Training post graduate) and a continuous training as well, in all cases articulating a theoretical part with a supervision component in service.

4) The training of technicians, although focusing primarily on teachers, should include all technicians involved in SOU (psychologists, physicians, nurses, social workers, operational workers, parents, etc.). It is recommended that the direction of SOU, in a convergence of efforts where the Ministry of Education and Science can take a lead in the management and profitability of the process (e.g. the establishment of protocols with Institutions of Higher Education and Training Centers valued teachers).

\subsection{Limitations of the Study}

One of the major limitations of the study was the shortage of time allowed to its accomplishment (3 months and a half). If more time had been allowed, researchers would have included a broader range of participants such as pupils, parents and private schools. There was an initial attempt to include them, but the participant rate was not enough and there was no time to insist on producing a higher answering rate, in relation to those participants.

On another side the research team would like to accomplish a larger set of local visit to schools, preferably staying in each school for a period of 1 - 2 days and addressing a broad range of participants. 
Finally, there is not (yet) a steady culture of a regular and smooth evaluation process in Portuguese institutions, therefore allowing the threat of social desirability. This issue should be addressed carefully and timely in the next evaluation.

\section{References}

Currie, C., Zanotti, C., Morgan, A., Currie, D., de Looze, M., Roberts, C., Samdal, O., Smith, O., \& Barnekow, V. (Eds.) (2012). Social Determinants of Health and Well-Being among Young People. Health Behaviour in School-Aged Children (HBSC) Study: International Report from the 2009/2010 Survey. Copenhagen: WHO Regional Office for Europe.

GTES-Grupo de Trabalho de Educação Sexual (2005). Relatório Preliminar do Grupo de Trabalho de Educação Sexual. www.min-edu.pt

GTES-Grupo de Trabalho de Educação Sexual (2007). Educação para a saúde nas escolas: relatório final. www.min-edu.pt M.E. \& M.S. (2000). Educação Sexual em Meio Escolar. Linhas Orientadoras. Lisboa: Editorial do Ministério da Educação.

Matos, M. G., \& Gaspar, T. (2002). Country Report: Gender and Smoking in Young People in Portugal. In M. Lambert (Coord.), Gender Differences in Smoking in Young People (pp. 107-120). Brussels: MIHP.

Matos, M. G., Gaspar, T., Vitória, P., \& Clemente, M. (2003). Adolescentes e o tabaco-rapazes e raparigas. Lisboa: Faculdade de Motricidade Humana/CPT/ Ministério da Saúde.

Matos, M. G., \& Simões, C. (2010). Sexualidade, Segurança e Sida. In Matos (Coord.), Sexualidade, Afectos e CulturaGestão de problemas de saúde em meio escolar (pp. 257-262). Lisboa: Coisas de Ler.

Matos, M. G., Sampaio, D., Baptista, I., \& Equipa Aventura Social, UTL and CMDT/UNL (2013). Adolescent’s Health Education and Promotion in Portugal: A Case Study of Planning for Sustainable Practice. In O. Samdal, \& L. Rowling (Eds.), The Implementation of Health Promoting Schools, Exploring the Theories of What, Why and How (pp. 123-126). New York: Routledge Taylor \& Francis Group.

Matos, M. G., Simões, C. Tomé, G., Camacho, I., Ferreira, M., Ramiro, L., Reis, M., \& Equipa Aventura Social (2011). A Saúde dos Adolescentes Portugueses-Relatório do Estudo HBSC 2010. ACS/FMH/UTL/CMDT-UNL.

Navidi, W. (2010). Principles of Statistics for Engineers and Scientists (1st ed.). New York, NY: McGraw-Hill.

Pickton, D. W., \& Wright, S. (1998). What's SWOT in Strategic Analysis? Strategic Change, 7, 101-109. http://dx.doi.org/10.1002/(SICI)1099-1697(199803/04)7:2<101::AID-JSC332>3.0.CO;2-6

Ramiro, L. (2013). A educação sexual na mudança de conhecimentos, atitudes e comportamentos sexuais dos adolescentes. Lisboa: Faculdade de Motricidade Humana da Universidade Técnica de Lisboa. (Unpublished)

https://www.repository.utl.pt/bitstream/10400.5/5862/1/Lucia_Ramiro_Dout.pdf

Reis, M. (2012). Promoção da saúde sexual em jovens universitários portugueses-conhecimentos e atitudes face à contraceção e à prevenção das ISTs. Lisboa: Faculdade de Motricidade Humana da Universidade Técnica de Lisboa. (Unpublished) https://www.repository.utl.pt/bitstream/10400.5/5169/1/Tese Doutoramento MartaReis 18dez2012.pdf

van Wijngaarden, J. D., Scholten, G. R., \& van Wijk, K. P. (2010). Strategic Analysis for Health Care Organizations: The Suitability of the SWOT-Analysis. International Journal of Health Planning and Management, 27, 34-49.

http://dx.doi.org/10.1002/hpm.1032 
Scientific Research Publishing (SCIRP) is one of the largest Open Access journal publishers. It is currently publishing more than 200 open access, online, peer-reviewed journals covering a wide range of academic disciplines. SCIRP serves the worldwide academic communities and contributes to the progress and application of science with its publication.

Other selected journals from SCIRP are listed as below. Submit your manuscript to us via either submit@scirp.org or Online Submission Portal.
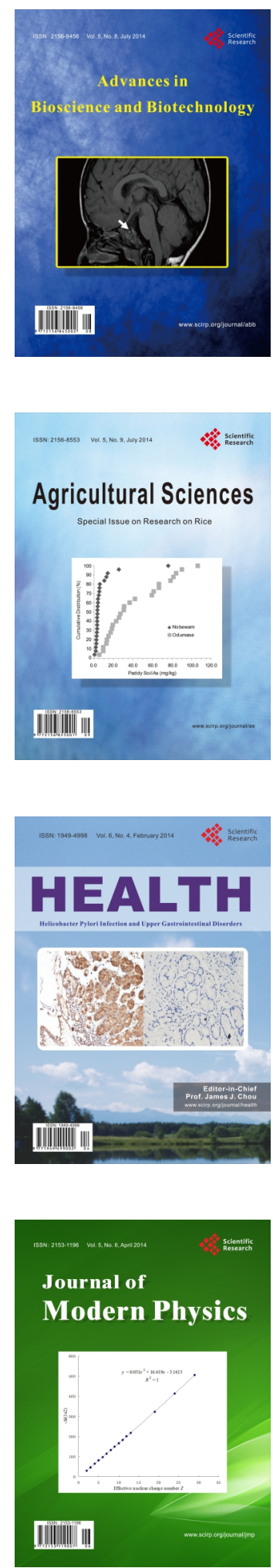
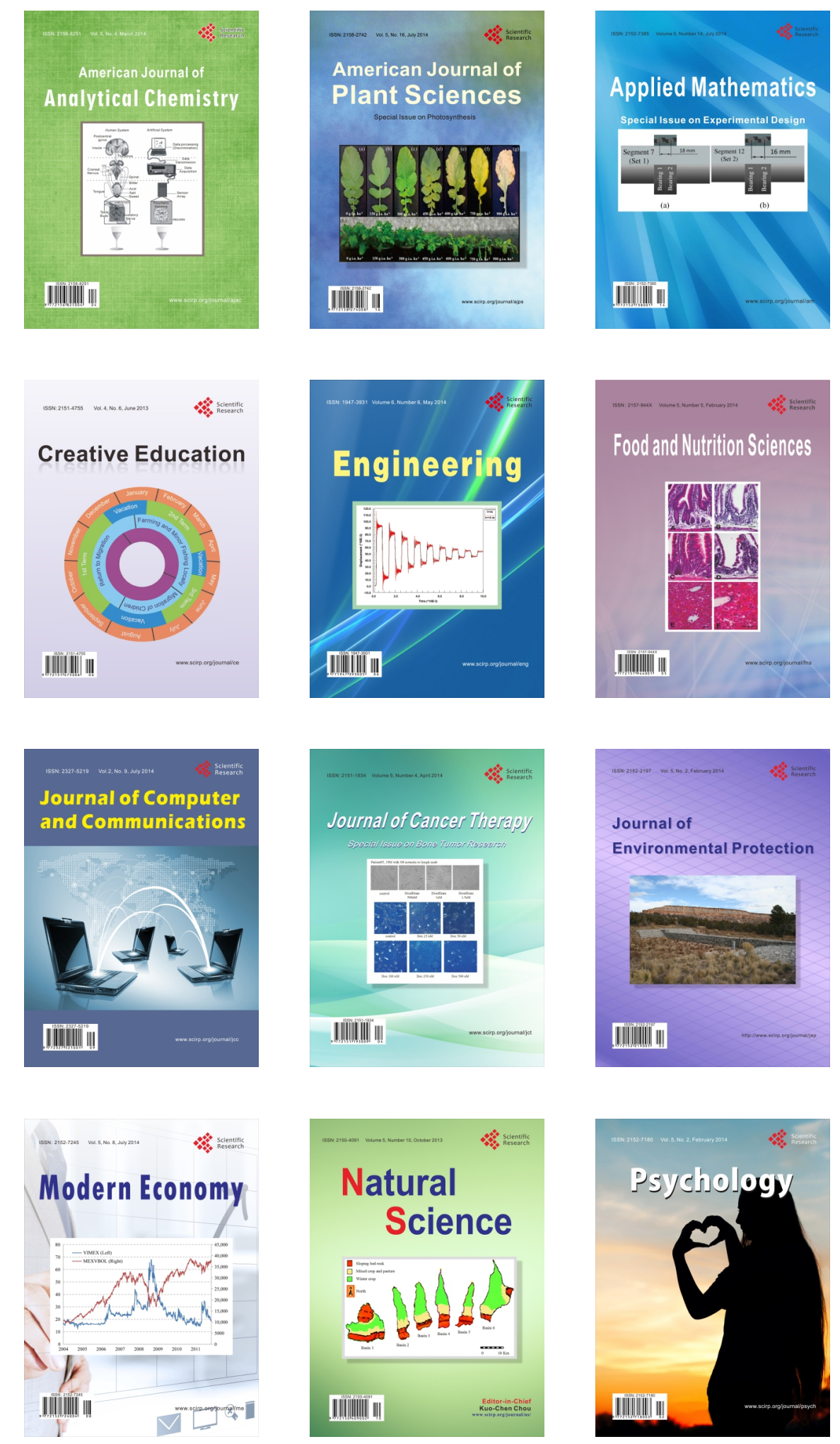